\title{
Analysis of Association between CT-assessed Body Composition and Survival Composition of Patients with Sepsis in EICU
}

\section{Tian Yun Xu}

First Affiliated Hospital of Anhui Medical University

He Zhang

First Affiliated Hospital of Anhui Medical University

Jie Zhi Li

First Affiliated Hospital of Anhui Medical University

Nan Wang ( $D$ 523601821@qq.com )

the Fourth Affiliated Hospital of Anhui medical univeisity https://orcid.org/0000-0002-0257-1865

Research article

Keywords: EICU, Computed Tomography, Sepsis, SMD, SMA, SAT, Mortality

Posted Date: January 29th, 2021

DOl: https://doi.org/10.21203/rs.3.rs-156786/v1

License: (c) (i) This work is licensed under a Creative Commons Attribution 4.0 International License. Read Full License 


\section{Abstract}

Background: The prevalence of sepsis among patients in the intensive care unit is high. Thus, the evaluation of prognosis in these patients is paramount. This study aimed to appraise the role of the abdominal composition quantified from computed tomography (CT) scan in predicting a 90-day mortality rate among patients with sepsis in the emergency intensive care unit (EICU).

Method: Through Cox regression analysis, the skeletal muscle density (SMD, skeletal muscle area (SMA), and subcutaneous adipose tissue area (SAT) assessed by the CT abdomen were associated with the 90day mortality rate, with adjustment to the acute physiology and chronic health assessment (APACHE II) score, sequential organ failure assessment (SOFA) score, and BMI. Linear regression was performed to analyze other clinical factors.

Result: The Cox regression analyses showed that compared with the non-survival group at 90-day, patients with a higher SMD (HR per $10 \mathrm{HU}=0.619 ; 95 \% \mathrm{Cl}=0.450-0.853 ; \mathrm{p}=0.003)$, SMA (HR per 10 $\left.\mathrm{cm}^{2}=0.870 ; 95 \% \mathrm{Cl}=0.781-0.969 ; p=0.011\right)$, and SAT $\left(\mathrm{HR}\right.$ per $10 \mathrm{~cm}^{2}=0.954 ; 95 \% \mathrm{Cl}=0.912-0.999$; $P=0.047$ ) were significantly associated with a lower 90-day mortality rate. These significant correlations persisted after adjusting for the BMI, APACHE II, and SOFA scores. Further analysis revealed gender differences in the SMD and skeletal muscle index (SMI) between the survival and the non-survival group.

Conclusion: The content of body composition assessed by an abdominal CT scan is highly associated with the 90-day mortality of patients with sepsis in the EICU, of which the SMD, SMA, and SAT represent valuable prognostic factors.

\section{Introduction}

Sepsis is associated with life-threatening organ dysfunction as a result of imbalances in the host response to an infection [1], which is a common clinical challenge faced by the emergency and critical care clinician. Sepsis contributes to a huge burden to the society and economy, with the mortality rate exceeding $25 \%$. Given the prevalence and impactful of this disorder, in 2016, the American Society of Intensive Medicine and the European Society of Intensive Medicine have jointly issued the 3rd international consensus on the definition and diagnostic criteria of sepsis [2].

Muscular atrophy is a serious sequela of critical illnesses. Low muscle density has been associated with poor prognosis [3]. In particular, muscle loss is related to higher hospitalization and mortality among patients in the ICU. Furthermore, patients who have survived following discharge from the ICU may also experience functional changes that affect their quality of life. Therefore, the concept of sarcopenia has been introduced in 2010 by the European Working Group on Sarcopenia in Older People [4], which is defined as a syndrome characterized by a progressive and comprehensive loss of skeletal muscle mass and strength. 
In recent years, studies have shown that skeletal muscle acts as an endocrine organ of cytokines and peptides that plays a key role in the inflammatory process [5]. Also, skeletal muscle content is of great significance to the nutritional status and prognostic risk assessment of ICU patients with sepsis. Given that the systemic inflammatory response represents a risk factor for muscle loss, this warrants further study to define the relationship between skeletal muscle content and survival rate in the presence of inflammatory response [6],to analyze whether skeletal muscle loss is related to mortality.To date, there is no research examining the influence of body composition on the prognostic evaluation of ICU patients with sepsis. Therefore, this study aimed to evaluate the association between body composition and 90day mortality among these patients.

\section{Methods}

\section{Patients and data}

This was a single-center, retrospective analysis of the abdominal body composition of critically ill patients with sepsis admitted to the EICU of Anhui Medical University from January 2015 to December 2018. Patient inclusion criteria for the study were 18 years of age or older, hospitalization in the EICU for at least 4 days, and at least one abdominal CT examination within 24 hours before or 4 days after admitting to the EICU. Patients were excluded if they were pregnant or diagnosed with chronic neuromuscular diseases.

Data including patient age, gender, weight, height, BMl, skeletal muscle density and area, visceral fat area and density, subcutaneous fat area and density, intermuscular fat area and density, the worst scores on APACHE II and SOFA within 24 hours of admission, laboratory indicators, 90-day survival rate, ventilation time, EICU length of stay (EICU-LOS), hospital length of stay, continuous renal replacement therapy (CRRT), Charlson comorbidity index (CCI) [7], and the nutrition risk in critically ill (NUTRIC) score [8] were collected. The survival prognostic information of patients discharged from the hospital before 30 days was followed up by telephone.

\section{CT scan analysis}

High accuracy for the analysis of the body composition of a single-slice abdominal CT scan at the level of the third lumbar vertebra (L3) has been previously demonstrated [9]. Based on the evaluation of magnetic resonance imaging (MRI), the skeletal muscle area at this level is closely related to the volume of skeletal muscle in the whole body [3]. In our study, patients' abdominal CT images were analyzed by experienced radiologists using the Mimics version 17 software (Fig. 1) [10]. Patients were excluded from the study if the quality of the CT images were low or the muscle integrity was damaged due to factors such as trauma or artifacts. The vertebral bone markers at the L3 level were used to ensure the reproducibility and consistency of measurements.

Varying ranges of $\mathrm{HU}$ value (Hounsfield) were used to define body compositions, with the $\mathrm{HU}$ of muscle ranging -29 to +150 , $\mathrm{HU}$ of intermuscular fatty tissue and subcutaneous fat tissue ranging -190 to -30 , and $\mathrm{HU}$ of visceral fatty tissue ranging -150 to $-50[3,11]$. SMD was evaluated by the average radiation 
muscle attenuation of the entire muscle at the L3 level, and the HU scale was a radioactivity scale that described the tissue density in CT scans [12]. By analyzing the bone density scale, a higher HU value indicated a higher skeletal muscle density and a lesser fat infiltration [13]. Given that the body composition content corresponded to the nutritional status and survival prognosis of patients with sepsis in the EICU, this was analyzed according to the primary endpoint of our study, which was the 90-day mortality rate. The secondary endpoints included ventilation time, length of hospital stay, norepinephrine dose, CRRT time, CCl score, and gender differences (Fig. 1).

\section{Statistical analysis}

A normality test was performed for all the continuous variables. To compare the survival and non-survival groups, the independent sample $t$ test was used for the normally distributed data, whereas the MannWhitney $U$ test was used to analyze non-normally distributed variables. Fisher's exact test and Chi2 test were used to analyze categorical variables. Following univariate analyses, BMI was added to the model to adjust for the severity of the disease (model 2), and then the APACHE II and SOFA scores were added to the second adjustment model (model 3). The 'age' included in the APACHE II was therefore not separately included in the adjustment model. Logistic regression and linear regression were used to explore the relationship between skeletal muscle area (SMA), skeletal muscle density (SMD), subcutaneous adipose tissue area (SAT), and the ventilation time, hospital stay, norepinephrine dose, CRRT duration, and CCI score. Kaplan-Meier chart was used to analyze the relationship between skeletal muscle index and 90-day mortality (divided into two groups according to the median) stratified by gender, and the log-rank test was performed to compare the survival curves between the two groups.

SPSS Statistics 23.0 is used for all the statistical analysis, and values were expressed as mean \pm standard deviation (SD) or median and quartile. All data were two-sided. A P-value of $<0.05$ was considered statistically significant.

\section{Results}

\section{Patients selection}

During the study period, A total of 1898 patients were included in the study, 460 patients met the clinical criteria for sepsis but only 128 patients fulfilled our study criteria for the abdominal CT scans. The quality of CT images was suboptimal in the subcutaneous fatty tissue in 4 patients, and another patient had surgery on the abdominal muscles. Therefore, a total of 123 patients with complete clinical data were included in our study (fig.2).

\section{Patient characteristics}

Table 1 reflects the patient's comorbidities and main infections, Table 2 contains the characteristics of 90-day survivors and non-survivors, Table 3 contains univariate analysis and adjusted models, Table 4 contains the correlation between skeletal muscle density, area, and subcutaneous fat tissue area with secondary results, and Table 5 shows the relationship between SMD and SMI of different genders and 90- 
day mortality. The basic demographics of patients were outlined in Table 1. Overall, the 90-day mortality rate was $35.8 \%$. When compared with the survival group, patients in the non-survival group were significantly older $(67 \pm 16$ vs $57 \pm 16$ years, $p=0.001)$, had higher APACHE II scores $(21 \pm 5$ vs $17 \pm 5, p$ $<0.001)$, and higher SOFA scores [10 (8-13) vs $\left.8(7-11) \mathrm{cm}^{2}, \mathrm{p}=0.005\right]$ (Table 2). Upon admission to the ICU, the average SMD of all patients was $30.21 \mathrm{HU}$, the average SMA was $124.61 \mathrm{~cm}^{2}$, and the average SAT was $112.85 \mathrm{~cm}^{2}$. The non-survival group had a lower SMD (26.7 \pm 9.3 vs $\left.32.2 \pm 9.3 \mathrm{HU}, p=0.003\right)$, lower SMA (114.8 \pm 27.4 vs $\left.130.1 \pm 30.9 \mathrm{~cm}^{2} ; \mathrm{p}=0.007\right)$, and also lower SAT $(96.1 \pm 65.4$ vs. $122.2 \pm 71.6$ $\mathrm{cm}^{2}, \mathrm{p}=0.043$ ) when compared with the survival group.

Table 1. Demographics of patients included in the study.

\begin{tabular}{|c|c|c|}
\hline Characteristics & \multicolumn{2}{|c|}{ Overall patients $(\mathrm{n}=123)$} \\
\hline Comorbidities & Total & प\%口 \\
\hline $\mathrm{AKI} / \mathrm{CKD}$ & 33 & 26.8 \\
\hline cerebrovascular disease & 32 & 26 \\
\hline diabetes & 30 & 24.3 \\
\hline heart failure & 25 & 20.3 \\
\hline connective tissue disease & 15 & 12.2 \\
\hline gastroduodenal ulcer & 14 & 11.3 \\
\hline tumor & 14 & 11.3 \\
\hline Others & 20 & 16.2 \\
\hline Focus of infection & Total & $\square \% \square$ \\
\hline Respiratory & 39 & 31.7 \\
\hline Hepatobiliary & 25 & 20.3 \\
\hline Urinary tract & 11 & 8.9 \\
\hline Others & 48 & 39 \\
\hline
\end{tabular}

AKI acute kidney injury, CKD chronic kidney diseases

Table 2. Comparisons of patient demographics between the survival and the non-survival groups. 


\begin{tabular}{|c|c|c|c|c|c|}
\hline & Survivors (79) & & Non-survivors & $(44)$ & \\
\hline & $\mathrm{M} / \mathrm{medium} / \mathrm{n}$ & $\overline{\mathrm{SD} / \mathrm{IQR} / \%}$ & $\mathrm{M} /$ medium/n & $\mathrm{SD} / \mathrm{IQR} / \%$ & value \\
\hline Age & 56.61 & .30 & 67.07 & 16.23 & 0.001 \\
\hline male $\llbracket n$ & 48 & $61 \%$ & 34 & $77 \%$ & 0.074 \\
\hline BMI & 21.60 & $\begin{array}{l}20.45- \\
22.60\end{array}$ & 21.23 & $\begin{array}{l}20.06- \\
22.17\end{array}$ & 0.317 \\
\hline APACHE II & 16.59 & & 21.36 & 5.08 & \\
\hline SOFA & 8 & $7-11$ & 10 & $8-13$ & 0.005 \\
\hline NUTRIC & 4 & $2-5$ & 5 & $5-7$ & \\
\hline PCT & 7.54 & $\begin{array}{c}3.36- \\
38.84\end{array}$ & 7.795 & $\begin{array}{c}3.89- \\
30.73\end{array}$ & 0.858 \\
\hline Charlson comorbidity index & 3 & 2 & 6 & 2 & \\
\hline $\begin{array}{l}\text { Length of hospital stay before } \\
\text { ICU admission, days }\end{array}$ & 0 & $0-1$ & 1 & $0-2$ & 0.391 \\
\hline $\begin{array}{l}\text { Time from ICU admission to } \\
\text { CT scan, days }\end{array}$ & 1 & $1-3$ & 2 & $1-4$ & 0.285 \\
\hline SMD (HU) & 32.15 & 9.26 & 26.74 & 9.25 & 0.002 \\
\hline SMA $\left(\mathrm{cm}^{2}\right)$ & 130.09 & & 114.76 & & 0.007 \\
\hline $\mathrm{SMI} \mathrm{cm} \mathrm{cm}^{2} / \mathrm{m}^{2}$ & 46.65 & 8.9 & 41.63 & & 0.004 \\
\hline IMAT (HU) & -59.26 & 5.28 & -57.21 & 6.53 & 0.075 \\
\hline IMAT $\left(\mathrm{cm}^{2}\right)$ & 13.10 & 6.44 & 14.91 & 7.62 & 0.166 \\
\hline SAT (HU) & -85.44 & 13.95 & -80.25 & & 0.074 \\
\hline SAT $\left(\mathrm{cm}^{2}\right)$ & 122.21 & 71.56 & 96.06 & 65.42 & 0.043 \\
\hline VAT (HU) & -82.85 & & -85.20 & $\begin{array}{c}-93.13, \\
-73.3\end{array}$ & 0.897 \\
\hline $\operatorname{VAT}\left(\mathrm{cm}^{2}\right)$ & 93.30 & 63.54 & 91.27 & 80.40 & 0.878 \\
\hline Length of ventilation & 6 & $0-10$ & 10 & $4-16$ & 0.002 \\
\hline ICU length of stay & 8 & $5-15$ & 10 & $6-16$ & 0.301 \\
\hline Hospital length of stay & 22 & $15-31$ & 15 & $11-23$ & 0.005 \\
\hline NA (mg) & 12 & $0-54$ & 80 & $12-410$ & \\
\hline CRRTロn & 11 & $14 \%$ & 15 & $34 \%$ & 0.012 \\
\hline
\end{tabular}

BMI body mass index,APACHE $\square$ Acute physiology and chronic health evaluation $\square$, SOFA sequential organ failure assessment,PCT procalcitonin,CCI Charlson comorbidity index, SMD skeletal muscle density,SMA skeletal muscle area,IMAT intermuscular adipose tissue,SAT subcutaneous adipose tissue,VAT visceral adipose tissue, SMI SMA/height2,NA noradrenaline,CRRT continuous renal replacement therapy

COX regression analysis (Table 3) demonstrated that higher SMD was associated with a lower 90-day mortality (hazard ratio, HR per $10 \mathrm{HU}=0.619 ; 95 \% \mathrm{Cl}=0.450-0.853 ; \mathrm{p}=0.003$ ). After adjusting for the confounding factors (SOFA and APACHE II), this significant association had persisted (HR per 10 $\mathrm{HU}=0.722 ; 95 \% \mathrm{Cl}=0.524-0.997 ; \mathrm{p}=0.048)$.

Table 3. Cox regression analyses: an association between SMD, SMA, or SAT and 90-day mortality. 


\begin{tabular}{|c|c|c|c|c|c|c|c|c|c|}
\hline \multirow[t]{2}{*}{$\begin{array}{l}\text { 90-day } \\
\text { mortality }\end{array}$} & \multicolumn{3}{|c|}{$\begin{array}{c}\text { Univariable } \\
N=123\end{array}$} & \multicolumn{3}{|c|}{$\begin{array}{l}\text { Model 2 } \\
\mathrm{N}=123\end{array}$} & \multicolumn{3}{|c|}{$\begin{array}{l}\text { Model 3 } \\
\mathrm{N}=123\end{array}$} \\
\hline & $\overline{\mathrm{HR}}$ & $95 \%$ & $\overline{\mathrm{P}}$ & $\overline{\mathrm{HR}}$ & $95 \%$ & $\bar{P}$ & $\overline{\mathrm{HR}}$ & $95 \%$ & $\overline{\mathrm{P}}$ \\
\hline $\begin{array}{c}\text { SMDhu (per } \\
10 \square\end{array}$ & 0.619 & $\begin{array}{l}0.450 \\
0.853\end{array}$ & 0.003 & 0.613 & $\begin{array}{l}0.442 \\
0.851\end{array}$ & 0.003 & 0.722 & $\begin{array}{l}0.524- \\
0.997\end{array}$ & 0.048 \\
\hline$\underset{10)}{\mathrm{SMAcm}^{2}}$ (per & 0.870 & $\begin{array}{l}0.781 \\
0.969\end{array}$ & 0.011 & 0.860 & $\begin{array}{l}0.768 \\
0.963\end{array}$ & 0.009 & 0.889 & $\begin{array}{l}0.797- \\
0.992\end{array}$ & 0.036 \\
\hline $\begin{array}{c}\mathrm{SATcm}^{2} \square \text { per } \\
10 \square\end{array}$ & 0.954 & $\begin{array}{l}0.912 \\
0.999\end{array}$ & 0.047 & 0.952 & $\begin{array}{l}0.907 \\
0.999\end{array}$ & 0.046 & 0.952 & $\begin{array}{l}0.914- \\
0.992\end{array}$ & 0.020 \\
\hline
\end{tabular}

Model 2 adjusts BMI; Model 3 adjusts SOFA, APACHE II.

Similarly, higher SMA was significantly associated with lower 90-day mortality (HR per $10 \mathrm{~cm}^{2}=0.870$; $95 \% \mathrm{Cl}=0.781-0.969 ; p=0.011$ ), and remained significant after adjusting for the confounding factors (HR per $\left.10 \mathrm{~cm}^{2}=0.889 ; 95 \% \mathrm{Cl}=0.797-0.992 ; \mathrm{p}=0.036\right)$.

Furthermore, higher SAT was also significantly correlated with a lower 90-day mortality rate (HR per 10 $\left.\mathrm{cm}^{2}=0.954 ; 95 \% \mathrm{Cl}=0.912-0.999 ; \mathrm{p}=0.047\right)$, which again, remained significant after adjusting for the confounding factors SOFA and APACHE II (HR per $\left.10 \mathrm{~cm}^{2}=0.952 ; 95 \% \mathrm{Cl}=0.914-0.992 ; \mathrm{p}=0.02\right)$.

\section{Analyses of secondary endpoints}

Higher SMD, SMA, and SAT were associated with lower CCI scores (Table 4). After adjusting for the APACHE II and SOFA scores, this correlation remained significant. The amount of norepinephrine was related to the SAT but this correlation was non-significant after adjusting for the confounding variables. There were significant gender differences in the SMD and skeletal muscle index (SMI) between the survival and the non-survival group, where the SMD and SMI were higher among the male survivors while this phenomenon was not observed in female patients (Table 4, Table 5 and fig.3).

Table 4. Logistic and linear regression analyses: an association between SMD, SMA, or SAT and secondary outcomes. 


\begin{tabular}{|c|c|c|c|c|c|c|}
\hline \multirow{3}{*}{ Length of ventilation } & \multicolumn{3}{|c|}{ Univariable } & \multicolumn{3}{|c|}{ Adjusts APACHE II and SOFA } \\
\hline & \multirow[t]{2}{*}{$\mathrm{OR} / \mathrm{B}$} & $95 \% \mathrm{Cl}$ & \multirow[t]{2}{*}{$\begin{array}{l}\mathrm{P} \\
\text { value }\end{array}$} & \multirow[t]{2}{*}{$\mathrm{OR} / \mathrm{B}$} & \multirow[t]{2}{*}{$95 \% \mathrm{Cl}$} & \multirow[t]{2}{*}{$\begin{array}{l}\mathrm{P} \\
\text { value }\end{array}$} \\
\hline & & & & & & \\
\hline $\begin{array}{l}\text { SMD per10HU } \\
\text { SMA per10 } \mathrm{cm}^{2}\end{array}$ & $\begin{array}{l}-1.133 \\
-0.088\end{array}$ & $\begin{array}{l}-2.867 \text { to } 0.601 \\
-0.637 \text { to } 0.460\end{array}$ & $\begin{array}{l}0.198 \\
0.751\end{array}$ & $\begin{array}{l}-0.727 \\
-0.001\end{array}$ & $\begin{array}{l}-2.332 \text { to } 0.878 \\
-0.507 \text { to } 0.505\end{array}$ & $\begin{array}{l}0.372 \\
0.997\end{array}$ \\
\hline $\begin{array}{l}\text { SAT per } 10 \mathrm{~cm}^{2} \\
\text { Hospital length of } \\
\text { stay }\end{array}$ & -0.013 & -0.251 to 0.225 & 0.917 & 0.038 & -0.181 to 0.257 & 0.734 \\
\hline $\begin{array}{l}\text { SMD per10HU } \\
\text { SMAper10 } \mathrm{cm}^{2}\end{array}$ & $\begin{array}{l}-0.038 \\
0.196\end{array}$ & $\begin{array}{l}-2.792 \text { to } 2.716 \\
-0.669 \text { to } 1.061\end{array}$ & $\begin{array}{l}0.978 \\
0.655\end{array}$ & $\begin{array}{l}0.134 \\
0.258\end{array}$ & $\begin{array}{l}-2.670 \text { to } 2.938 \\
-0.622 \text { to } 1.137\end{array}$ & $\begin{array}{l}0.925 \\
0.563\end{array}$ \\
\hline $\begin{array}{l}\text { SAT per10 } 0 \mathrm{~cm}^{2} \\
\text { NA }(\mathrm{mg})\end{array}$ & 0.085 & -0.290 to 0.460 & 0.654 & 0.073 & -0.309 to 0.454 & 0.706 \\
\hline SMD per10HU & -18.219 & \multirow{4}{*}{$\begin{array}{l}-56.121 \\
19.682 \\
-14.269 \\
9.636 \\
-10.720 \\
-0.547\end{array}$} & 0.343 & -11.437 & \multirow{4}{*}{$\begin{array}{l}-46.868 \text { to } \\
23.998 \\
-12.287 \\
10.012 \\
-9.270 \text { to } 0.252\end{array}$} & 0.524 \\
\hline SMAper $10 \mathrm{~cm}^{2}$ & -2.317 & & 0.702 & -1.137 & & 0.840 \\
\hline SAT per $10 \mathrm{~cm}^{2}$ & -5.634 & & 0.030 & -4.509 & & 0.063 \\
\hline \multicolumn{5}{|l|}{ CRRT, n } & & \\
\hline $\begin{array}{l}\text { SMD per10HU } \\
\text { SMA per10 } \mathrm{cm}^{2}\end{array}$ & $\begin{array}{l}0.319 \\
0.111\end{array}$ & $\begin{array}{l}0.868-2.181 \\
0.970-1.286\end{array}$ & $\begin{array}{l}0.174 \\
0.125\end{array}$ & $\begin{array}{l}0.330 \\
0.113\end{array}$ & $\begin{array}{l}0.880-2.201 \\
0.968-1.294\end{array}$ & $\begin{array}{l}0.158 \\
0.129\end{array}$ \\
\hline $\begin{array}{l}\text { SAT per10 } \mathrm{cm}^{2} \\
\text { CCI }\end{array}$ & 0.056 & $0.995-1.125$ & 0.071 & 0.062 & $1.000-1.133$ & 0.051 \\
\hline $\begin{array}{l}\text { SMD per10HU } \\
\text { SMA per10 } \mathrm{cm}^{2}\end{array}$ & $\begin{array}{l}-0.559 \\
-0.016\end{array}$ & $\begin{array}{l}-0.948 \text { to }-0.169 \\
-0.283 \text { to }-0.037\end{array}$ & $\begin{array}{l}0.005 \\
0.011\end{array}$ & $\begin{array}{l}-0.459 \\
-0.137\end{array}$ & $\begin{array}{l}-0.827 \text { to }-0.093 \\
-0.253 \text { to }-0.021\end{array}$ & $\begin{array}{l}0.015 \\
0.021\end{array}$ \\
\hline SAT per10 $\mathrm{cm}^{2}$ & -0.061 & -0.015 to -0.008 & 0.025 & -0.055 & -0.105 to -0.005 & 0.032 \\
\hline
\end{tabular}

Table 5. The comparison of body composition between the survival and the non-survival groups of different genders.

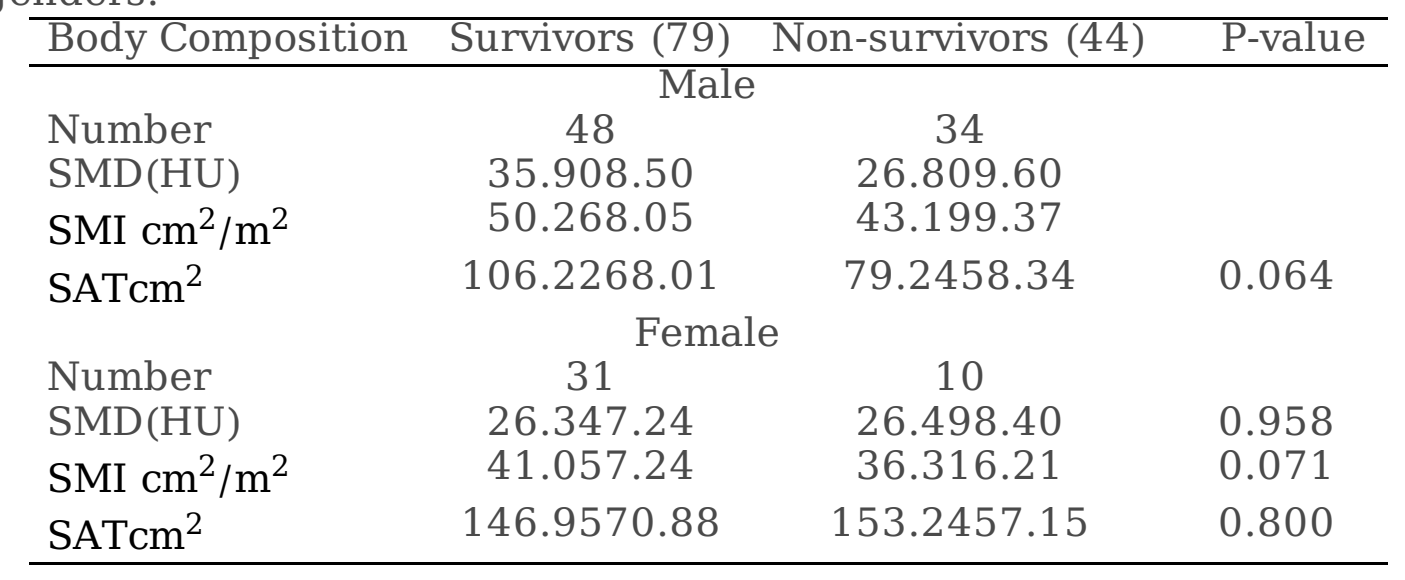

\section{Discussion}


Our study has demonstrated that the lower body compositions including the SMA, SMD, and SAT of EICU patients with sepsis are significantly associated with a poorer 90-day overall survival, which is consistent with previous studies and indicating that the severity of skeletal muscle loss is an important predictor of patient prognosis [14-16]. Specifically, among critically ill patients, our findings were consistent with the study by Wilhelmus et al., confirming that the density and area of skeletal muscle play an important role in evaluating the survival prognosis [3]. EICU patients often suffer from malnutrition and systemic inflammation, which contributes to a decline in their immune function leading to an imbalance in response to infection and sepsis [19]. Coupled with significant skeletal muscle loss, these factors will lead to higher hospitalization and mortality rates $[17,18]$. At present, varying cut-off values have been used to define abdominal skeletal sarcopenia, and the optimal cut-off value for predicting patient survival through sarcopenia remains unknown [20]. Nevertheless, the prognostic significance of sarcopenia based on Martin et al.'s definition is currently widely used in cancer patients [21-23].

This study revealed that higher subcutaneous adipose tissue was associated significantly with a lower 90-day mortality rate among EICU patients with sepsis. Interestingly, other studies have observed a lower hospital mortality rate in severely ill patients who were otherwise overweight and obesity [24], while a large observational cohort study of 154308 patients has provided more solid evidence for this phenomenon of obesity paradox [25]. Some authors believe that adipose tissue may play an important role in the immune system of EICU patients under physiological stress [17]. Another explanation for this obesity paradox may be that when patients are exposed to intense inflammation and metabolic stress, adipose tissue may act as a nutritional reserve that gives survival advantage. Furthermore, specific hormones in obesity have also been shown to play a role in influencing mortality [26]. Bornstein and colleagues reported a positive correlation between the leptin concentration and the survival rate of patients with sepsis, suggesting the role of leptin in the adaptive response to critical illness $[26,27]$.

A large number of randomized controlled trials have shown that norepinephrine shares the same clinical efficacy as other vasoactive drugs but it has fewer complications such as cardiac arrhythmias [28]. In our study, a linear relationship between the area of subcutaneous adipose tissue and the amount of norepinephrine was demonstrated. When the confounding variables have been adjusted, this relationship disappeared, indicating the association of the amount of norepinephrine to the severity of the disease.

The Charlson Comorbidity Index (CCl) is currently one of the most commonly used tools in comorbidity assessment $[7,29]$. This study demonstrated a significant association between $\mathrm{CCl}$ and body composition. The study by Gong et al. highlighted the important role of $\mathrm{CCl}$ in assessing skeletal muscle mass and physical function, which correlated a higher the $\mathrm{CCl}$ score with a lower muscle area, providing essential information and evidence for the diagnosis of sarcopenia [7].

It is generally recognized that the body compositions and the metabolisms of fat and protein differ between men and women [30-32], but few have explored the relationship between body composition of different genders and in patients with sepsis in critical settings. Here, we analyzed and compared the differences in body composition of different genders between the survival and the non-survival groups of 
patients with sepsis in EICU, and found that in men, the skeletal muscle index and skeletal muscle density of the survival group were significantly higher. In women, no such difference was observed. Further studies are warranted to delineate the pathophysiological pathways that may explain the influence of gender differences in skeletal muscle and survival prognosis in critically ill patients with sepsis. In preclinical models and healthy participants, gender-based differences in the fiber type composition of skeletal muscle, function, and muscle fatigue sensitivity have been widely reported [33,34]. Also, the study by Choi et al. has shown that compared with females, male patients with advanced cancer and muscle wasting were significantly associated with mortality [35].

Our study represented the first analysis associating body composition with survival outcomes of patients with sepsis in EICU. This was a retrospective study carried out in a tertiary hospital in China with no variability in races [36] of the included patients. However, selection bias was apparent, which included only those patients with sepsis who had undergone abdominal CT scans. Patients' Also, nutritional supports of these patients were not explored.

\section{Conclusions}

The body composition assessed by the abdominal CT scan is significantly associated with the 90-day survival prognosis of EICU patients with sepsis, which is independent of BMI, SOFA, and APACHE II scores, especially among male patients. Therefore, body composition should be measured and incorporated into the overall assessment of the nutritional status and prognosis in clinical practice.

\section{Abbreviations}

AKI: acute kidney injury; CKD: chronic kidney diseases; BMI: body mass index; APACHE II: Acute physiology and chronic health evaluation II; SOFA: sequential organ failure assessment; PCT procalcitonin; CCl: Charlson comorbidity index; SMD: skeletal muscle density; SMA: skeletal muscle area; IMAT: intermuscular adipose tissue; SAT: subcutaneous adipose tissue; VAT: visceral adipose tissue; SMI: SMA/height2; NA: noradrenaline; CRRT: continuous renal replacement therapy

\section{Declarations}

\section{Acknowledgements}

None

\section{Authors' contributions}

$\mathrm{YX}$ analyzed the data and wrote the paper. $\mathrm{HZ}$ and $\mathrm{JL}$ collected the date.NW checked the integrity of the data and the accuracy of the data analysis.All authors read and approved the final manuscript.

\section{Funding}


This research was supported by the Scientific Research Fund of Anhui Medical University (2020xkj211).

\section{Availability of data and materials}

The datasets used and analyzed during the current study are available from the corresponding author on reasonable request.

\section{Ethics approval}

The study was approved by the ethics committee of the First Affiliated Hospital, Anhui Medical University (No.Quick-PJ2020-16-08). Informed consent was waived because the study was retrospective in design. The study was performed in accordance to the Helsinki Declaration.All patients'records were anonymized and de-identified prior to analysis.

\section{Consent for publication}

Not applicable

\section{Competing interests}

The authors declare that they have no competing interests.

\section{References}

[1] Cao Y, Chai YF, Deng Y, Fang BJ, Liu MH, Lu ZQ, et al. Guidelines for the emergency treatment of sepsis/septic shock in China. Journal of Clinical Emergency. 2018;19(09):567-588.

[2] Singer M, Deutschman CS, Seymour CW, Shankar-Hari M, Annane D, Bauer M, et al. The Third International Consensus Definitions for Sepsis and Septic Shock (Sepsis-3). JAMA. 2016;315(8):801-10. doi: 10.1001/jama.2016.0287.

[3] Looijaard WG, Dekker IM, Stapel SN, Girbes AR, Twisk JW, Oudemans-van Straaten HM, et al. Skeletal muscle quality as assessed by CT-derived skeletal muscle density is associated with 6-month mortality in mechanically ventilated critically ill patients. Crit Care. 2016;20(1):386. doi: 10.1186/s13054-016-1563-3.

[4] Cruz-Jentoft AJ, Baeyens JP, Bauer JM, Boirie Y, Cederholm T, Landi F, et al. European Working Group on Sarcopenia in Older People. Sarcopenia: European consensus on definition and diagnosis: Report of the European Working Group on Sarcopenia in Older People. Age Ageing. 2010;39(4):412-23. doi: 10.1093/ageing/afq034.

[5] Romagnoli C, Pampaloni B, Brandi ML. Muscle endocrinology and its relation with nutrition. Aging Clin Exp Res. 2019;31(6):783-792. doi: 10.1007/s40520-019-01188-5.

[6] Dolan RD, Almasaudi AS, Dieu LB, Horgan PG, McSorley ST, McMillan DC. The relationship between computed tomography-derived body composition, systemic inflammatory response, and survival in 
patients undergoing surgery for colorectal cancer. J Cachexia Sarcopenia Muscle. 2019;10(1):111-122. doi: $10.1002 / j c s m .12357$.

[7] Gong G, Wan W, Zhang X, Liu Y, Liu X, Yin J. Correlation between the Charlson comorbidity index and skeletal muscle mass/physical performance in hospitalized older people potentially suffering from sarcopenia. BMC Geriatr. 2019;19(1):367. doi:10.1186/s12877-019-1395-5.

[8] Rahman A, Hasan RM, Agarwala R, Martin C, Day AG, Heyland DK. Identifying critically-ill patients who will benefit most from nutritional therapy: Further validation of the "modified NUTRIC" nutritional risk assessment tool. Clin Nutr. 2016;35(1):158-162. doi: 10.1016/j.clnu.2015.01.015.

[9] MacDonald AJ, Greig CA, Baracos V. The advantages and limitations of crosssectional body composition analysis. Curr Opin Support Palliat Care. 2011;5:342-9.

[10] Braunschweig CA, Sheean PM, Peterson SJ, Gomez Perez S, Freels S, Troy KL, et al. Exploitation of diagnostic computed tomography scans to assess the impact of nutrition support on body composition changes in respiratory failure patients. JPEN J Parenter Enteral Nutr. 2014;38(7):880-5. doi:

10.1177/0148607113500505. Epub 2013 Aug 23.

[11] Mourtzakis M, Prado CM, Lieffers JR, Reiman T, McCargar LJ, Baracos VE. A

practical and precise approach to quantification of body composition in cancer patients using computed tomography images acquired during routine care. Appl Physiol Nutr Metab. 2008;33:997-1006.

[12] Aubrey J, Esfandiari N, Baracos VE, Buteau FA, Frenette J, Putman CT, et al. Measurement of skeletal muscle radiation attenuation and basis of its biological variation. Acta Physiol (Oxf). 2014;210(3):489-97. doi: 10.1111/apha.12224.

[13] Goodpaster BH, Kelley DE, Thaete FL, He J, Ross R. Skeletal muscle attenuation determined by computed tomography is associated with skeletal muscle lipid content. J Appl Physiol. 2000;89:104-10.

[14] Shibahashi K, Sugiyama K, Kashiura M, Hamabe Y. Decreasing skeletal muscle as a risk factor for mortality in elderly patients with sepsis: A retrospective cohort study. J Intensive Care. 2017;5:8.

[15] Peterson SJ, Braunschweig CA. Prevalence of sarcopenia and associated outcomes in the clinical setting. Nutr Clin Pract. 2016;31:40-48.

[16] Martin CM, Hill AD, Burns K, Chen LM. Characteristics and outcomes for critically ill patients with prolonged intensive care unit stays. Crit. Care Med. 2005;33:1922-1927.

[17] Weijs PJ, Looijaard WG, Dekker IM, Stapel SN, Girbes AR, Oudemans-van Straaten HM, et al. Low skeletal muscle area is a risk factor for mortality in mechanically ventilated critically ill patients. Crit Care. 2014;18(2):R12. doi: 10.1186/cc13189. 
[18] Moisey LL, Mourtzakis M, Cotton BA, Premji T, Heyland DK, Wade CE, et al. Nutrition and Rehabilitation Investigators Consortium (NUTRIC). Skeletal muscle predicts ventilator-free days, ICU-free days, and mortality in elderly ICU patients. Crit Care. 2013;17(5):R206. doi: 10.1186/cc12901.

[19] Reisinger KW, van Vugt JL, Tegels JJ, Snijders C, Hulsewé KW, Hoofwijk AG, et al. Functional compromise reflected by sarcopenia, frailty, and nutritional depletion predicts adverse postoperative outcome after colorectal cancer surgery. Ann Surg. 2015;261(2):345-52. doi:

$10.1097 /$ SLA.0000000000000628.

[20] Nishigori T, Tsunoda S, Obama K, Hisamori S, Hashimoto K, Itatani Y, et al. Optimal Cutoff Values of Skeletal Muscle Index to Define Sarcopenia for Prediction of Survival in Patients with Advanced Gastric Cancer. Ann Surg Oncol. 2018;25(12):3596-3603. doi: 10.1245/s10434-018-6728-7.

[21] Martin L, Birdsell L, Macdonald N, Reiman T, Clandinin MT, McCargar LJ, et al. Cancer cachexia in the age of obesity: skeletal muscle depletion is a powerful prognostic factor, independent of body mass index. J Clin Oncol. 2013;31(12):1539-47. doi: 10.1200/JC0.2012.45.2722.

[22] Kudou K, Saeki H, Nakashima Y, Edahiro K, Korehisa S, Taniguchi D, et al. Prognostic Significance of Sarcopenia in Patients with Esophagogastric Junction Cancer or Upper Gastric Cancer. Ann Surg Oncol. 2017;24(7):1804-1810. doi: 10.1245/s10434-017-5811-9.

[23] Sharma P, Zargar-Shoshtari K, Caracciolo JT, Fishman M, Poch MA, Pow-Sang J, et al. Sarcopenia as a predictor of overall survival after cytoreductive nephrectomy for metastatic renal cell carcinoma. Urol Oncol. 2015;33(8):339.e17-23. doi: 10.1016/j.urolonc.2015.01.011.

[24] World Health Organization: Obesity: preventing and managing the global epidemic: report of a WHO consultation. World Health Organ Tech Rep Ser 2000;894:i-253.

[25] Pickkers P, de Keizer N, Dusseljee J, Weerheijm D, van der Hoeven JG, Peek N. Body mass index is associated with hospital mortality in critically ill patients: an observational cohort study. Crit Care Med. 2013;41:1878-1883.

[26] Oliveros H, Villamor E. Obesity and mortality in critically ill adults: a systematic review and metaanalysis. Obesity (Silver Spring). 2008;16(3):515-521. doi:10.1038/oby.2007.102

[27] Bornstein SR, Licinio J, Tauchnitz R, Engelmann L, Negrão AB, Gold P, et al. Plasma leptin levels are increased in survivors of acute sepsis: associated loss of diurnal rhythm, in cortisol and leptin secretion. J Clin Endocrinol Metab. 1998;83(1):280-3. doi: 10.1210/jcem.83.1.4610.

[28] Polito A, Parisini E, Ricci Z, Picardo S, Annane D. Vasopressin for treatment of vasodilatory shock: an ESICM systematic review and meta-analysis. Intensive Care Med. 2012;38(1):9-19. doi:10.1007/s00134011-2407-x. 
[29] Durham-Lee JC, Wu Y, Mokkapati VU, Paulucci-Holthauzen AA, Nesic O. Induction of angiopoietin-2 after spinal cord injury. Neuroscience. 2012;202:454-64. doi: 10.1016/j.neuroscience.2011.09.058.

[30] Yoon SL, Grundmann O, Williams JJ, Gordan L, George TJ Jr. Body composition changes differ by gender in stomach, colorectal, and biliary cancer patients with cachexia: Results from a pilot study. Cancer Med. 2018;7(8):3695-3703.

[31] Montalvo RN, Counts BR, Carson JA. Understanding sex differences in the regulation of cancerinduced muscle wasting. Curr Opin Support Palliat Care. 2018;12(4):394-403. doi: $10.1097 /$ SPC. 0000000000000380 .

[32] Blaak E. Gender differences in fat metabolism. Curr Opin Clin Nutr Metab Care. 2001;4(6):499-502. doi: 10.1097/00075197-200111000-00006.

[33] Haizlip KM, Harrison BC, Leinwand LA. Sex-based differences in skeletal muscle kinetics and fibertype composition. Physiology (Bethesda). 2015;30(1):30-9. doi: 10.1152/physiol.00024.2014.

[34] Bouffard J, Yang C, Begon M, Côté J. Sex differences in kinematic adaptations to muscle fatigue induced by repetitive upper limb movements. Biol Sex Differ. 2018;9(1):17. doi: 10.1186/s13293-0180175-9.

[35] Choi Y, Oh DY, Kim TY, Lee KH, Han SW, Im SA, et al. Skeletal Muscle Depletion Predicts the Prognosis of Patients with Advanced Pancreatic Cancer Undergoing Palliative Chemotherapy, Independent of Body Mass Index. PLoS One. 2015 Oct 5;10(10):e0139749. doi: 10.1371/journal.pone.0139749.

[36] Taaffe DR, Cauley JA, Danielson M, Nevitt MC, Lang TF, Bauer DC, et al. Race and sex effects on the association between muscle strength, soft tissue, and bone mineral density in healthy elders: the Health, Aging, and Body Composition Study. J Bone Miner Res. 2001;16(7):1343-52. doi: 10.1359/jbmr.2001.16.7.134.

\section{Figures}




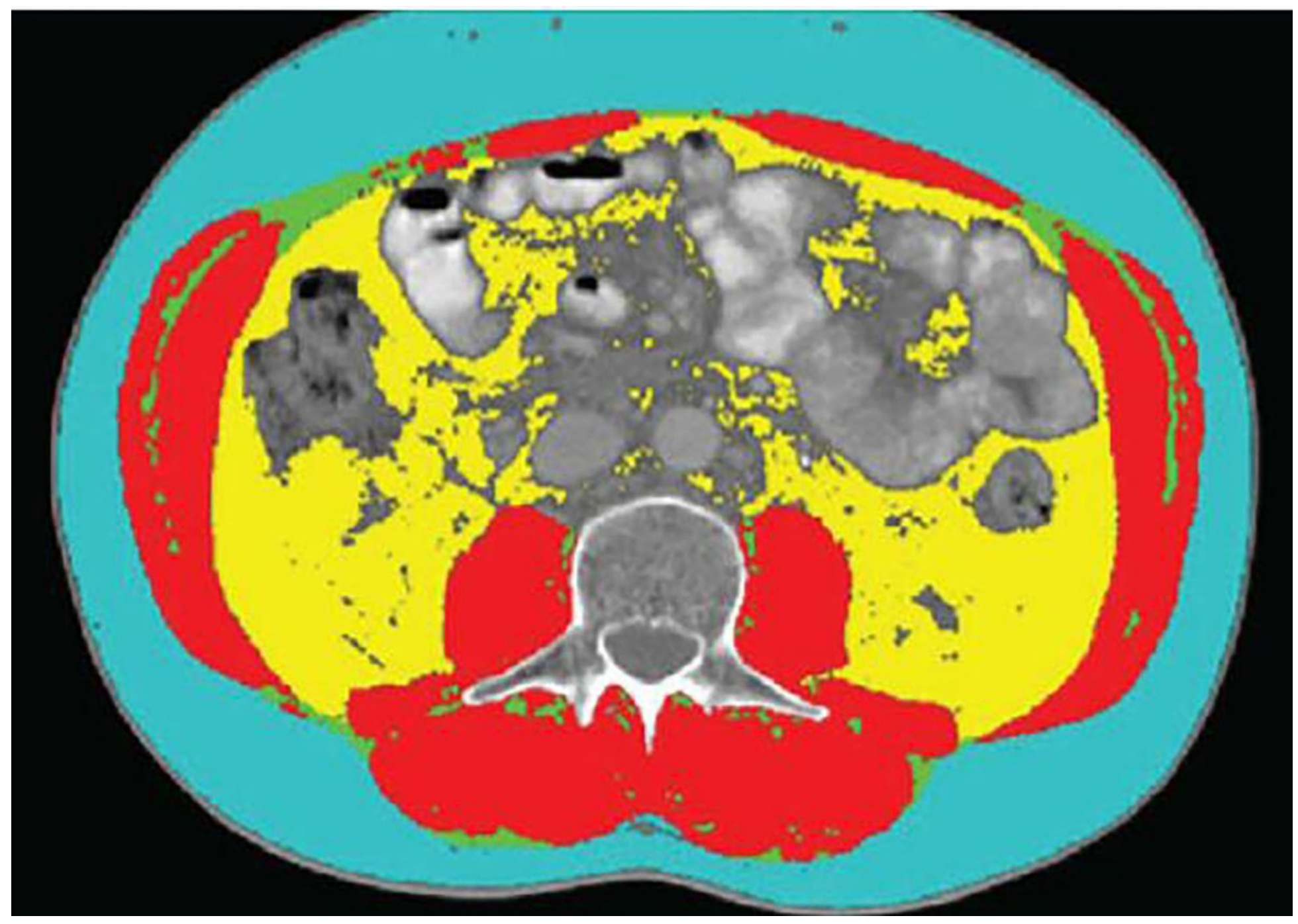

Figure 1

An Example of a CT slice at the L3 level to determine the body composition. SMD(red),VAT(yellow),SAT(bule),IMAT(green). 
From January 2015 to December 2018, more than 1,800 patients were admitted to the EICU

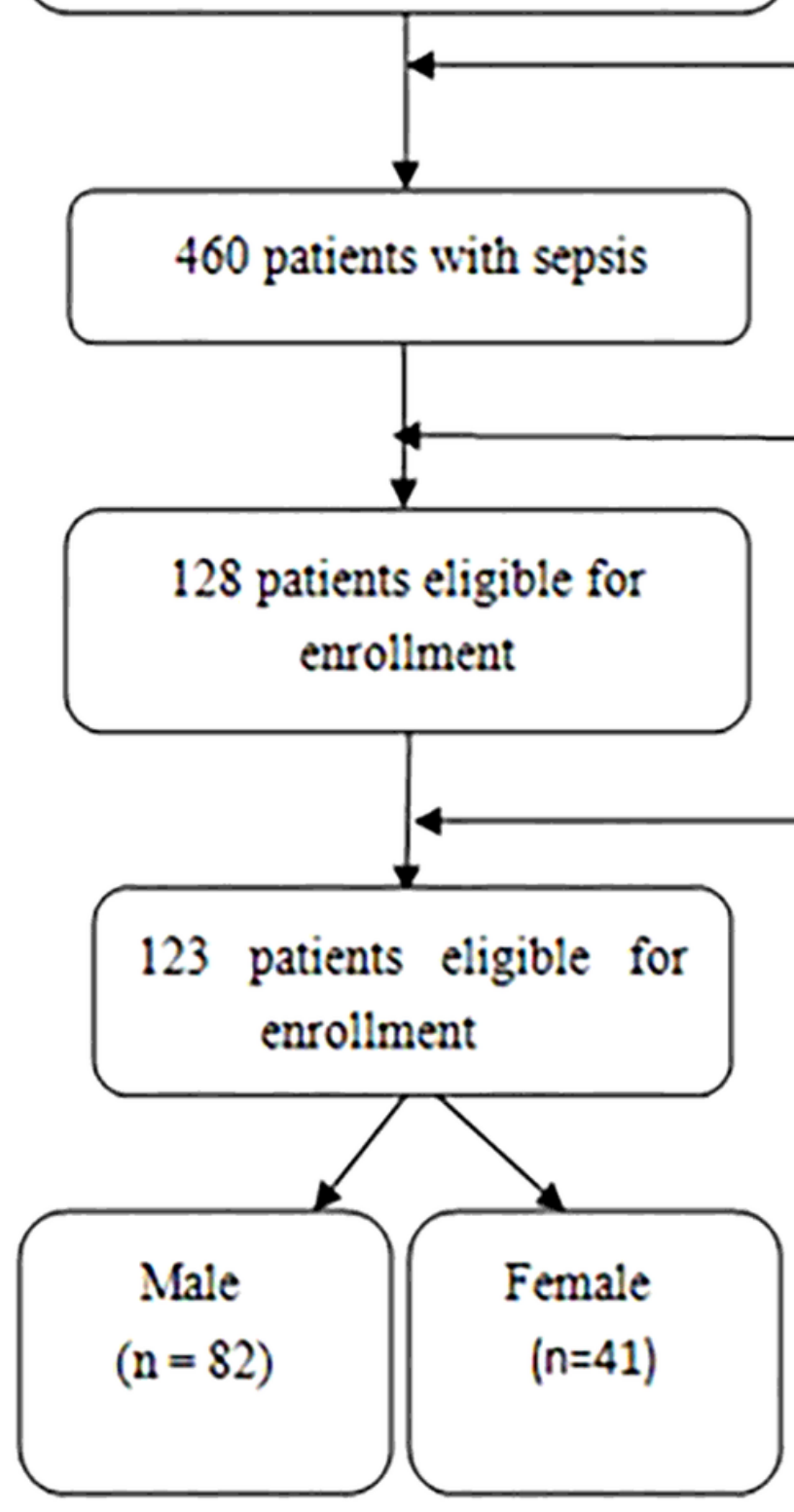

Meet the diagnostic criteria for sepsis: China sepsis / septic shock Emergency Treatment Guidelines (2018) definitions and standards

\section{At least one abdominal CT scan}

5 CT image subcutaneous adipose tissue area is blocked

Figure 2

Flow chart of patient selection for the study. 
(a)

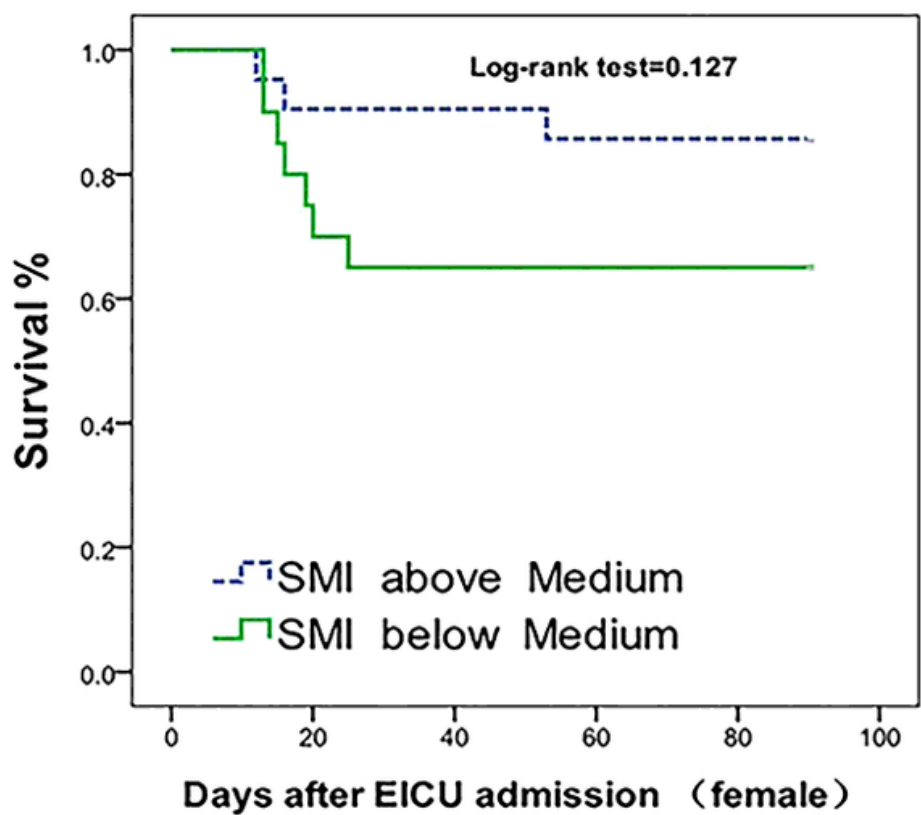

(b)

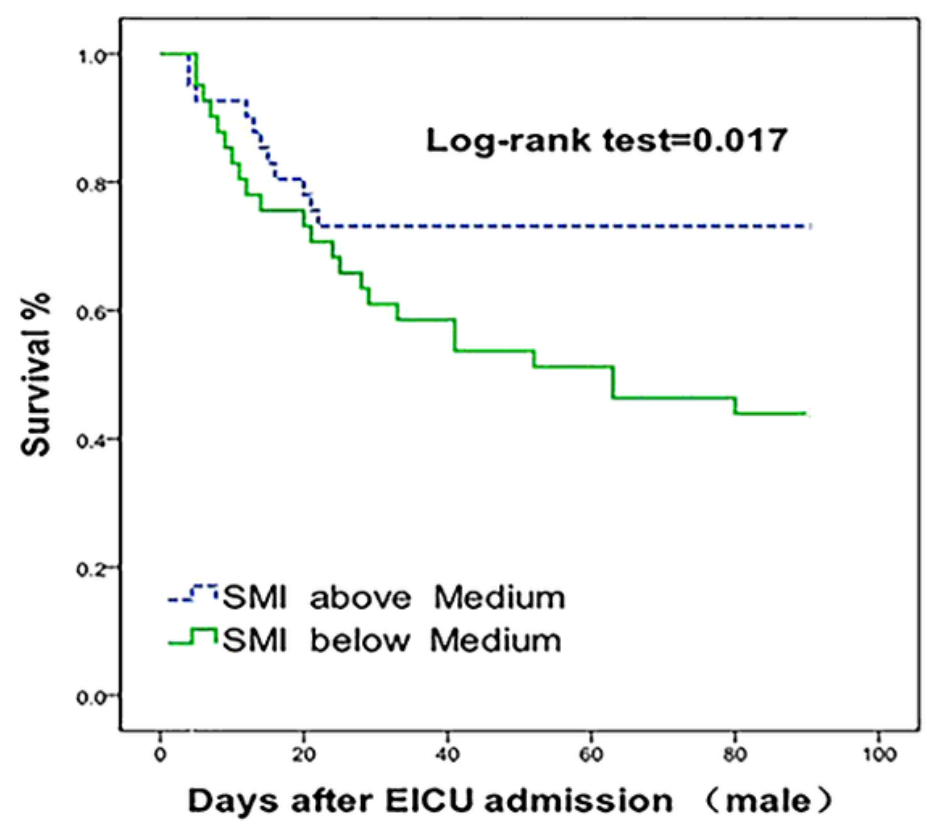

Figure 3

Kaplan-Meier Charts illustrated the association between the SMI and the mortality rate of different genders. 